\title{
Investigation on Flexural strength of Polymer nanocomposites modified by MWCNT and Glass fiber
}

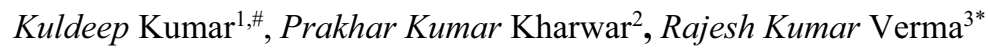 \\ ${ }^{1,3}$ Materials \& Morphology Laboratory, Department of Mechanical Engineering, \\ Madan Mohan Malaviya University Technology, Gorakhpur, Uttar Pradesh 273010, India \\ ${ }^{2}$ Mechanical Engineering Department, Sobhasaria Group of Institution, Sikar,332001 India
}

\begin{abstract}
The glass-reinforced laminated composite is widely used in place of conventional structural materials. The glass fiber composites demonstrate outstanding strength in the uniaxial direction. The effect of carbon nanotube reinforcement percentage on the flexural strength of glass-reinforced polymer composites is investigated in this article. The flexural strength of the final laminates has been found to improve by reinforcing the Carbon nanotube. The small incorporation of MWCNT improves the flexural strength up to $51.3 \%$. The $1.0 \mathrm{wt} . \%$ MWCNT reinforcement into GFRP shows the $51.3 \%$ improvement into flexural strength in comparison to GFRP composites. MWCNTs plays a prominent role to enhance the mechanical features of the developed samples. The SEM image is used to examine the nature and mechanics of failure. This study highlights the effect of carbon-based nanomaterial on the glass fiber reinforced epoxy composites.
\end{abstract}

\section{Introduction}

Composite materials combined with two or more materials and produce different properties from the parent material. The advantages of fiber-reinforced fiber composite are useful in nearly every engineering application[1]. Glass fiber is widely preferred among the different fibers due to its availability and outstanding feature to enhanced mechanical properties[2]-[5].The mechanical and chemical behavior of a fiber-reinforced composite mainly depends on the nature of the fiber and its modulus, chemical reactiveness, matrix strength, and interlayer bonding strength between fiber and matrix[6]. With appropriate compositions and optimal fiber orientation, desired properties are obtained, and the characteristics of GFRP provide higher stiffness than aluminum [7]. The glass fiber reinforcements are introduced in the matrix phase to improve the mechanical and tribological properties of the composites. Glass fiber has been used as replacement reinforcement for various conventional materials such as metals andis excessively used in the aerospace and automobile industries [8]. The technical application of glass fiber includes aircraft and instruments used in sports such as golf shafts, helmets, etc. Glass fiber has several advantages, including a high strength-to-weight ratio, a high stiffness-to-weight ratio, etc.[9]. While advantageous, the glass fiber reinforced polymers also exhibit brittle behaviors, and GFRP composites possess low fracture toughness. Also, among GFRP

*Correspondingauthor:rkvme@mmmut.ac.in composites, the main reason for fracture and failure is matrix cracking [10]-[12]. To improve these conditions,nanomaterials are incorporated to increase the toughness properties of the composites. In series, some researchers have studied the manufacturing aspect of glass/polymer composites. Kamar et al. [13] studied the effect of Graphene Nanoparticles in the glass-reinforced composite's mechanical properties. Flexural properties of the materials were found to increase with the addition of Nanoparticles. CNTs are used to modify the epoxy resin structure and improve mechanical characteristics such as flexural modulus, flexural strength, and toughness. Wang et al.[12]performed impact tests on different epoxymodified GFRP laminates with varying ratios of weight of glass fiber. The composites were designed to improve the properties regarding damage-resistant under impact loadings. The study revealed that impact responses were enhanced, and there was less case of breakage, debonding, pull-out, etc., when MWCNTs were added to the epoxy composites. Seyhan et al. [14] analyzed the fracture toughness of GFRP samples reinforced with $0.1 \%$ of MWCNT in order to evaluate the fracture properties. The interlaminar shear strength and fracture toughness values were significantly improved with a reinforcement of MWCNTs compared to neat GFRPs. Zhang et al. [15] used 0.4, 0.75, and 1.1 wt.\% of MWCNTs to be reinforced in the epoxy matrix of GFRP to enhance the mechanical characteristics in tensile indentation. Sample with $0.75 \%$ weight shows higher tensile strength with minimum damage induced 
in the composite, while 0.4 wt.\% GFRP samples provide more flexural strength in comparison to GFRP samples. Mahato et al. [16] added different weight $\%$ of MWCNTs such $(0.1 \%, 0.3 \%$, and 0.5 wt. $\%)$ in GFRP composites to study the tensile behavior during which different crosshead speeds were used. The tensile strength has been found to increase linearly from 0.1 to 0.3 wt. $\%$ but at different higher weights of $0.3-0.5$ wt.\% study found a decrement in tensile strength. The optimum value of tensile strength was obtained at 0.3 wt.\% of nanocomposite samples.

The above literature survey shows that GFRP composites play anessential role in substituting conventional structural material. MWCNT is widely accepted among different carbon-based nanomaterials in the form of supplements to epoxy matrix. The incorporation of nanomaterial significantly enhances the mechanical properties of laminated composites. Therefore, this article investigated the flexural behavior and strength under three-point bending mode for different MWCNT reinforcement $\%$ into glass fiber composites. Further SEM analysis was performed on the fractured sample to examine the fracture behavior of composites under three points bending mode.

\section{Materials and Methodology}

\subsection{Fabrication of MWCNT incorporate GFRP/epoxy nanocomposite}

The fabrication of MWCNT/glass fiber reinforced epoxy nanocomposite was done by the Hand layup method[17]-[19]. A 200 GSM glass fiber is used as a fabric material. MWCNT is used as a filler to improve their interfacial adhesive properties between fiber and matrix material of developed composites. The properties of MWCNT nanofiller materials and GFRP are mentioned in Table 1 and Table 2. The MWCNT was varied at three different weight fractions, 1, 2, and 3 wt. \% with acetone and dispersed for 1 hour to obtain a proper distribution of MWCNTs with reduced agglomerations. The dispersed MWCNT was mixed with epoxy Lapox resin 500, employing a high-speed mechanical stirrer for 1 hour. The mixture of epoxy and MWCNT was cooled at ambient temperature. After that, the mixture was immersed in an ultrasonic bath for 45 minutes at a frequency of $40 \mathrm{kHz}$. After that, the hardener is added at a ratio of 10:1 in mixed epoxy and MWCNTs. As shown in Fig.1, the samples are fabricated by the hand layup method size of $100 \times 100 \times 5 \mathrm{~mm}$.

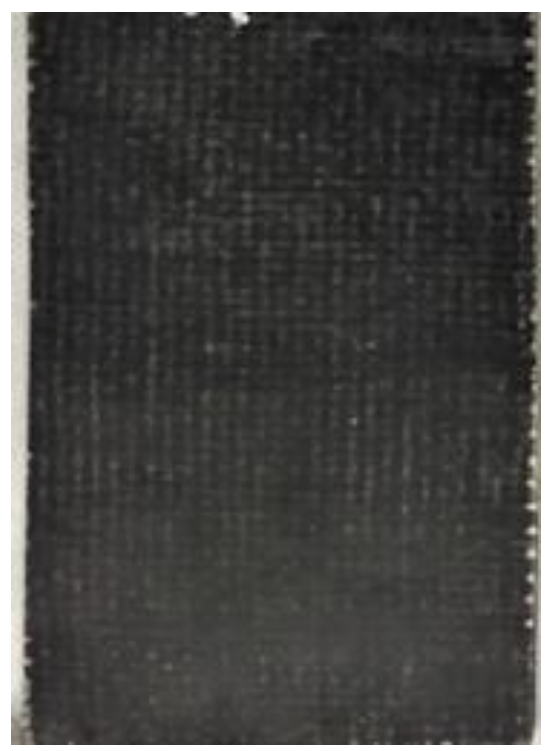

Fig. 1. Prepared sample

Table1. MWCNT specifications

\begin{tabular}{|c|c|c|}
\hline S.N. & Factors & Features \\
\hline 1 & Form & $\begin{array}{c}\text { Multiwall Carbon } \\
\text { Nanotube }\end{array}$ \\
\hline 2 & Purity & $99 \%$ \\
\hline 3 & $\begin{array}{c}\text { Average } \\
\text { Diameter }\end{array}$ & $10-15 \mathrm{~nm}$ \\
\hline 4 & Average Length & $5 \mu \mathrm{m}$ \\
\hline
\end{tabular}

Table 2 Physical and mechanicalproperties of GFRP

\begin{tabular}{|c|c|}
\hline Material & E- Glass \\
\hline Diameter $(\mu \mathrm{m})$ & 10 \\
\hline Tensilestrength $(\mathrm{GPa})$ & 3.45 \\
\hline Young'sModulus $(\mathrm{GPa})$ & 72.4 \\
\hline Density $\left(\mathrm{g} / \mathrm{cm}^{3}\right)$ & 2.58 \\
\hline Elongation at failure $\%$ & 4.8 \\
\hline Poisson ratio & 0.23 \\
\hline
\end{tabular}

\subsection{Specimen Testing}

As shown in Fig. 3, the MWCNT reinforced GFRP composites flexural test was carried out as per ASTM standard ASTM D7264 $(150 \times 13 \times 3)$ [20]. Flexural tests have been conducted at ambient temperature on the Universal Testing Machine (INSTRON- 3382), with a maximum load cell of $100 \mathrm{kN}$ as shown in Fig. 2.In three-point bending, flexural strength and flexural modulus have been computed. For each composition, three samples were tested. 


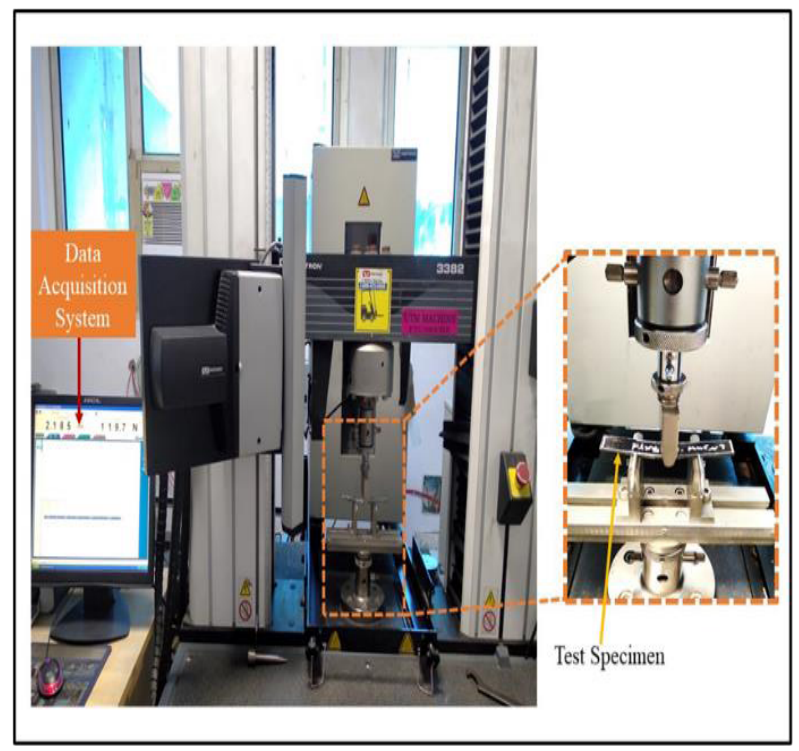

Fig. 2. Universal Testing Machine
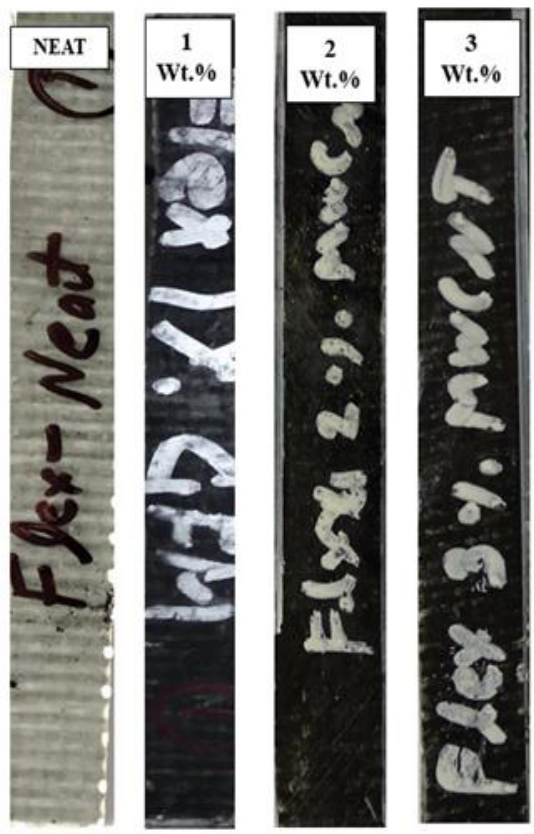

Fig. 3.Preparedsample as ASTM D7264

\section{Result and Discussion}

\subsection{XRD analysis}

This study highlights the crystallographic information ofMWCNT modified GFRP composite and neat GFRP composite using wide-angle X-ray diffraction (WAXD) on a Bruker D8 Advance diffractometer with monochromatized $\mathrm{Cu} \mathrm{Ka}$ radiation at $0.154 \mathrm{~nm}$. [21].

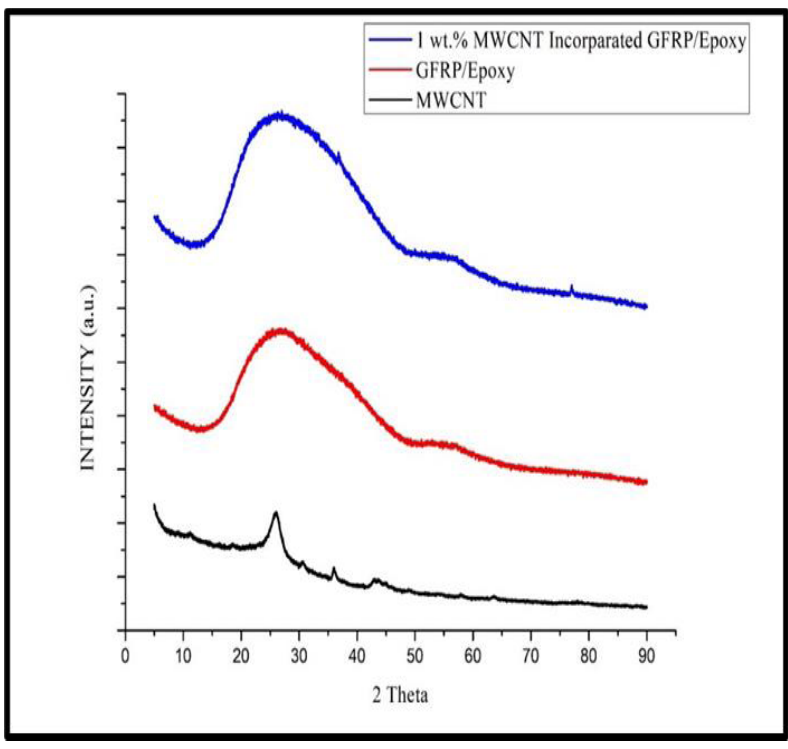

Fig. 4. XRD of Pure MWCNT, GFRP/epoxy, and 1 wt.\% MWCNT GFRP/epoxy

As decipated in Fig. 4 the High peaks confirm the graphitic planet 26.2 degrees and smaller peaks at 30 degrees, 36 degrees, and 43.2 degrees. At a $2 \theta$ value of 22.50, both GFRP- epoxy and MWCNT-GFRP-epoxy composites show a strong peak. This indicates that several layers of MWCNT have formed. The intercalation of epoxy chains between the MWCNT is responsible for the wide peak centered at $2 \theta=22.50$. The peak difference at 35 degrees and 75 degrees in GFRP-epoxy composite and MWCNT-GFRP-epoxy composite shows the interaction with MWCNT. The XRD results further suggest that the MWCNT dispersion in the composites is homogenous[22]-[24].

\subsection{Flexural Behavior}

The prepared specimen examines under three-point bending mode for examination of flexural behavior of the specimen. Fig.5 and 6 shows the stress-strain behavior of $0,1.0,2.0$ and 3.0 wt.\% of MWCNT reinforced GFRP composites. The flexural strength was calculated and showed in thefigure, and it is found that incorporating MWCNT into the GFRP composites system increases flexural strength[25], [26]. It is observed that the maximum flexural strength was achieved at 1.0 wt.\% of MWCNT, and further, the adding nanomaterial increases the tendency of agglomeration, which is acts as the crack propagation site. The maximum $51.3 \%$ improvement in flexural strength can be achieved at $1.0 \mathrm{wt} . \%$ of MWCNT and 2.0 wt. $\%$ and 3.0 wt.\% MWCNT reinforcement enhanced the flexural strength by $19.04 \%$ and $29.20 \%$, respectively. The SEM analysis was performed on the different fractured samples. As shown in Fig. 7 the SEM analysis observed that the increasing filler leads to increased constraint between polymer chains, resulting in a decrease in chain length over a critical length and a decrease in flexural strength[27]-[29]. 


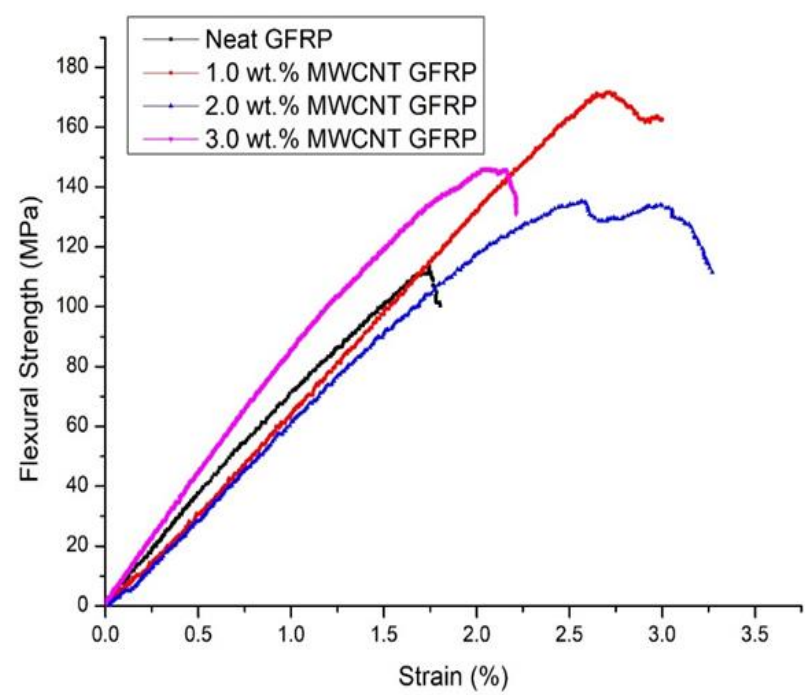

Fig. 5. Stress-Strain Behavior of MWCNT reinforced GFRP composites

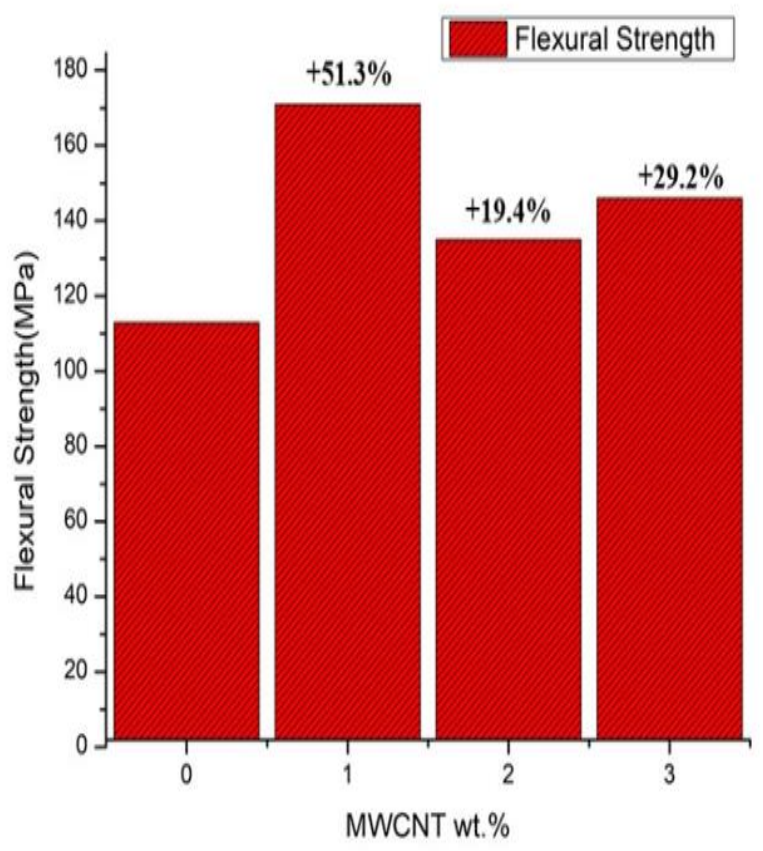

Fig. 6.Flexural strength with respect to MWCNT wt.\%
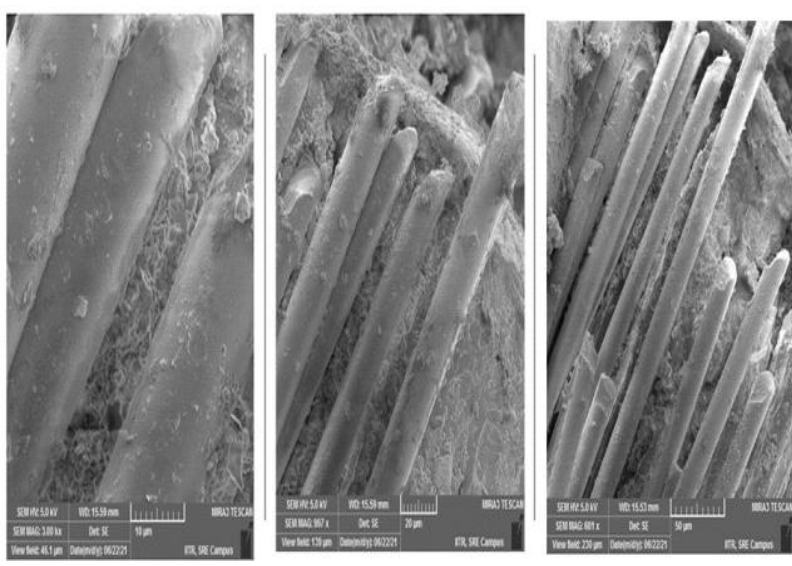

Fig. 7. SEM image of Fractured Sample (a) 1.0 wt. \% MWCNT (b) 2.0 wt.\% MWCNT (c) 3.0 MWCNT wt.\%

\section{Conclusion:}

This work highlights the flexural strength of the polymer composites modified by MWCNT. The addition of MWCNT significantly enhances the mechanical strength of the developed samples. A comprehensive analysis was proposed to investigate the manufacturing aspect of the developed specimens. Based on the obtained results, the following conclusion can be drawn:

1) The MWCNT with different concertation were effectively dispersed in the epoxy matrix using an ultrasonic process.

2) The 1.0 wt.\% MWCNT reinforcement into GFRP shows the $51.3 \%$ improvement into flexural strength in comparison to GFRP composites. Further adding of MWCNT lowers the flexural strength due to higher wt.\% of MWCNT increases agglomeration tendency, which initiates the crack propagation.

3) The reinforcement of MWCNT into epoxy matrix increases the flexural strength by $51.3 w t . \%, 19.4$ wt.\%, and 29.20 wt. $\%$

\section{Reference}

[1] M. Tehrani, A. Y. Boroujeni, T. B. Hartman, T. P. Haugh, S. W. Case, and M. S. Al-Haik, Compos. Sci. Technol., 75 42, (2013)

[2] R. K. P. and B. C. R. D S Kumar*, M J Shukla, K K Mahato, D K Rathore, construction and building material, 23174 (2015)

[3] R. P. Behera, P. Rawat, and K. K. Singh, Mater. Today Proc.5, 8176( 2018),

[4] A. I. Azmi, R. J. T. Lin, and D. Bhattacharyya, Int. J. Adv. Manuf. Technol., 67, 701 (2013).

[5] A. Tabatabaeian and A. R. Ghasemi, "Polym. Bull., vol. 776563 (2020)

[6] R. K. P. and B. C. R. D S Kumar*, M J Shukla, K K Mahato, D K Rathore, journal of aerospace engineering 7562 (2015)

[7] R. K. P. and B. C. R. D S Kumar*, M J Shukla, K K Mahato, D K Rathore,journal of aerospace engineering 31076 (2015).

[8] D. Kumar, K. K. Singh, and R. Zitoune, $A d v$. Manuf. Polym. Compos. Sci., 2, 47( 2016)

[9] K. K. Panchagnula and P. Kuppan, Journal of Materials Research and Technology, 8336 (2019)

[10] M. Shekarchi, E. M. Farahani, M. Yekrangnia, and T. Ozbakkaloglu, Fire Saf. J., 115, 10 (2020)

[11] K. K. Singh, S. K. Chaudhary, and R. Venugopal, Polym. Eng. Sci., 59, 248,( 2019)

[12] P. Wang et al., Mater. Sci., 50, 5978 (2015)

[13] N. T. Kamar, M. M. Hossain, A. Khomenko, M. Haq, L. T. Drzal, and A. Loos, Compos. 
Part A Appl. Sci. Manuf., 7082 (2015)

[14] A. Tugrul Seyhan, M. Tanoglu, and K. Schulte, Fract. Mech., vol. 75, 185151 (2008)

[15] X. Zhang et al., Mater. Des., 92, 621 (2015)

[16] S. N. Kane, A. Mishra, and A. K. Dutta, J. Phys. Conf. Ser., 755, 178, (2016)

[17] T. E. Tay, Appl. Mech. Rev 561 (2003)

[18] R. K. P. and B. C. R. D S Kumar*, M J Shukla, K K Mahato, D K Rathore, "Preface: International Conference on Recent Trends in Physics 755 75, (2013)

[19] R. K. P. and B. C. R. D S Kumar*, M J Shukla, K K Mahato, D K Rathore,journal of aero engineering, 2057, 75,(2015)

[20] R. K. P. and B. C. R. D S Kumar*, M J Shukla, K K Mahato, D K Rathore,149 75 (2015) 